\title{
Exploring teachers' motivation to teach: A multisite study on the associations with the work climate, students' motivation, and teaching approaches
}

\author{
Cesar A. Orsini DDS, MEd, FHEA, DHPE ${ }^{1}$ () ～～Jorge A. Tricio DDS, FHEA, PhD ${ }^{1} \quad \mid$ \\ Cristina Segura DDS, EdM ${ }^{2} \quad$ Doris Tapia DDS, MEd $^{3}$
}

${ }^{1}$ Faculty Development Office, Faculty of Dentistry, Universidad de los Andes, Universidad de los Andes, Santiago, Chile

${ }^{2}$ Instituto de Odontoestomatología, Escuela de Odontología, Facultad de Medicina, Universidad Austral de Chile, Santiago, Chile

${ }^{3}$ Department of Dentistry, Faculty of Medicine and Dentistry, Universidad de Antofagasta, Antofagasta, Chile

Correspondence

Dr Cesar A. Orsini, Facultad de Odontología, Universidad de los Andes, Monseñor Álvaro de Portillo 12455, Las Condes, Santiago, Chile.

Email: cesar.orsini@gmail.com

\begin{abstract}
Purpose: Using Self-determination Theory, the purpose was to determine whether work climate, students' motivation, and teachers' basic psychological needs could predict clinical teachers' autonomous and controlled motivation to teach and whether clinical teachers' motivations could predict student- and teacher-centered teaching approaches
\end{abstract}

Methods: A correlational cross-sectional study was conducted in 2018 across 3 Dental Schools in Chile, in which 206 clinical teachers participated (80.4\% response rate). Data were collected on demographic characteristics and 5 self-reported questionnaires measuring teachers' perceptions of the work climate, students' motivation, the satisfaction and frustration of their basic psychological needs, motivation to teach, and teaching approaches. Data were analyzed using bivariate correlations and structural equation modeling.

Results: Alpha coefficients were acceptable (0.701-0.948). Correlation and structural equation modeling analyses showed that teachers' perceiving a work climate characterized by a supportive supervisor-teacher relationship and students' autonomous motivation, predicted the satisfaction of their basic psychological needs leading to autonomous motivation to teach. Autonomous motivation to teach, in turn, predicted a student-centered teaching approach. These results were controlled for the confounding effects of age, gender, teaching experience, and type of university.

Conclusions: These results suggest that clinical teachers' optimal motivation is of paramount importance for promoting an adequate learning environment. Therefore, efforts should be made to understand and foster different aspects that promote clinical teachers' satisfaction of their basic psychological needs and autonomous motivation, especially regarding the role of teachers' supervisors and how teachers perceive their students' motivation.

\section{K E Y W O R D S}

dental education, teacher motivation, teaching approaches, self-determination theory, work climate 


\section{1 | INTRODUCTION}

Teaching in dentistry is a challenging task, where clinicians are expected to teach and are accountable for patient safety during students' training; however, they are also expected to lead, manage, and act as motivators with their students. In this sense, teachers' own motivation to teach plays a vital role in students' learning experiences. ${ }^{1}$ Recent literature has shown that teachers' interpersonal style and feedback may contribute to enhance students' motivation toward their studies and promote aspects such as deep learning, positive emotions, and better performance. ${ }^{2-5}$ Therefore, highly motivated teachers may be more likely to develop a learning climate which supports students' optimal motivation. ${ }^{6,7}$ Educational research, however, has mostly focused on students' motivation, paying little attention to teachers' motivation and the crucial role it has on the reasons why clinicians teach, how they experience their teaching role, and how this influences students' learning. ${ }^{1}$

One approach to understand teachers' motivation is looking at it through the lens of the Self-determination Theory (SDT), which focuses on the reasons why someone engages in a particular task. ${ }^{8}$ SDT differentiates between controlled and autonomous motivation rather than seeing it as a single quantity measure (i.e., more or less motivation). On the one hand, when teachers experience controlled motivation, they engage in activities predominantly due to external reasons, such as social or material rewards, avoiding punishment, or internal or external pressure. ${ }^{9}$ For instance, a clinician may put extra efforts on delivering a physiology lecture mainly because she or he wants to maintain a certain standard and obtain approval from her or his supervisor, colleagues, and students. Research has shown positive associations between teachers' controlled motivation, burnout, and a teaching approach characterized by being authoritative, demanding compliance, and motivating through pressure. ${ }^{10-12}$ On the other hand, when teachers' experience autonomous motivation, they predominantly engage because they find activities genuinely interesting or give value to them. ${ }^{9}$ For instance, a clinician may put extra efforts on the supervision and feedback of students performing minor oral surgery procedures mainly because she or he considers this task as relevant, engaging, and energizing. Previous studies have shown positive associations between teachers' autonomous motivation, self-efficacy, and a teaching approach characterized by being receptive, and providing students' with choice, constructive feedback, and rationale for the proposed learning activities. ${ }^{11-13}$

Therefore, being motivated may not necessarily lead to positive behavioral and psychological outcomes for clinical teachers; what matters is which type of motivation is driving behavior. While these types of motivation coexist within an individual, what should be aimed is to experience predom- inantly autonomous motivation. ${ }^{14}$ Consequently, in order to facilitate autonomous motivation, SDT posits that teachers' should perceive their work environment as supportive of their basic psychological needs of autonomy (feeling one has choices and concurs with work tasks), competence (feeling a sense of self-efficacy in their teaching role), and relatedness (feeling a sense a connectedness or belongingness with important others). On the contrary, a work environment that frustrates these needs will likely lead to experience controlled motivation. 5,9

Previous research in other educational domains has identified contextual factors from teachers' work environment that impact their motivation through the satisfaction or frustration of their basic psychological needs. ${ }^{1}$ These include factors such as the relationship established between teachers and supervisors, and how teachers perceive students' behavior and motivation toward their courses. ${ }^{15,16}$ So far, however, teachers' motivation quality along with its antecedents and consequences have not yet been investigated in dental education.

This study, therefore, set out to understand better clinical teachers' motivation to teach by exploring how contextual factors from the teaching environment influence motivation, which in turn influence behaviors toward teaching. Specifically, we tested how the work climate, perception of students' motivation, and teachers' basic need satisfaction and frustration predict teachers' autonomous and controlled motivation, and how these types of motivation predict teaching approaches.

We examined the following hypotheses, as presented in Figure 1:

1. Teachers' perception of the work climate (characterized by a supportive relationship with their supervisors) and teachers' perception of their students' motivation as autonomous over controlled can be used as (positive) predictors of teachers' satisfaction over the frustration of their basic psychological needs in the workplace.

2. Teachers' satisfaction over the frustration of their basic psychological needs can be used as a (positive) predictor of teachers' autonomous over controlled motivation to teach.

3. Teachers' autonomy over controlled motivation to teach can be used as a (positive) predictor of a student-centered (or conceptual change) over a teacher-centered (or information transfer) teaching approach.

This research is expected to advance the growing area of research on motivation in health profession education and complement the research conducted on motivational aspects of health professions' students, which may play a pivotal role to improve teachers' and students' performance and wellbeing. 


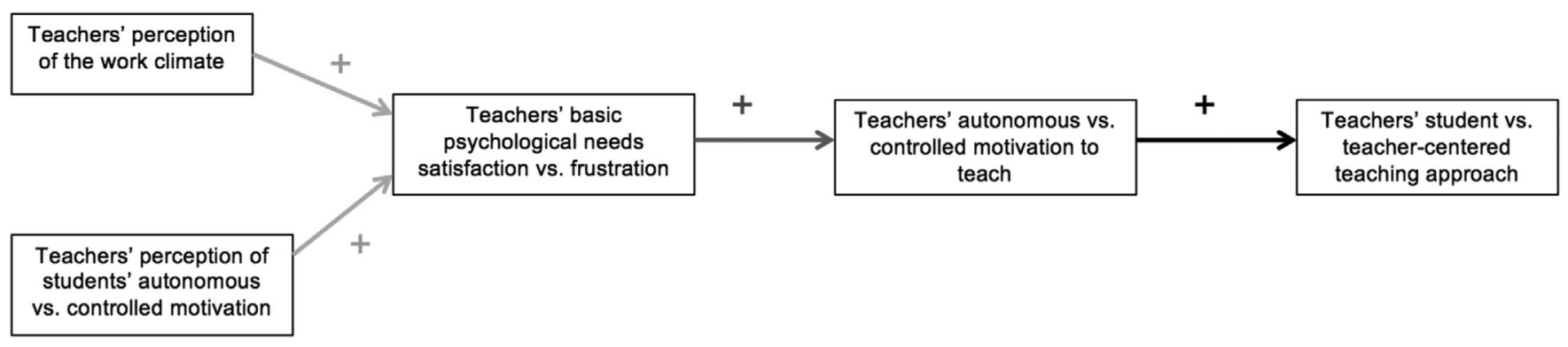

F I G U R E 1 Hypothesized model depicting the expected associations between determinants and consequences of teachers' motivation to teach. Note: Light gray paths symbolize hypothesis 1, dark gray path symbolizes hypothesis 2, and black path symbolizes hypothesis 3

\section{2 | METHODS}

\section{1 | Participants and procedures}

We conducted a correlational cross-sectional study in 2018 across 3 Chilean private and public Dental Schools, at the Universidad de Los Andes, Universidad Austral, and Universidad de Antofagasta. These are all members of the Association for Dental Education in Chile (ACHEO) and, therefore, deliver similar discipline-based curricula. The Ethics Institutional Review Board of the Universidad de Los Andes approved the study protocol (reference number CECFM 201508).

All clinical teachers, full- and part-time, were invited to participate $(\mathrm{n}=256)$. However, an a priori power analysis was conducted with the aim of being able to identify small to medium effects and to reduce the odds of a Type II error in our results. This resulted in a minimum sample size of 176 teachers (alpha $=0.05$, power $=0.80, \mathrm{G}^{*}$ Power software version 3.1.9.2). ${ }^{17}$

Teachers were asked to answer 5 anonymized paper-andpencil questionnaires from the published literature. They were first contacted by email informing about the study and inviting them to participate. Our research team delivered the questionnaires during teachers' weekly meetings. Teachers were asked to return the questionnaires to the faculty administrative office. One email reminder to return the questionnaires was sent after 15 days, and no incentives for participation were offered. The questionnaires asked for self-reported data, based on Likert scales, and were adapted to refer to the dental education context previous to data collection and analyses. These questionnaires have shown acceptable reliability and validity in previous studies using similar samples. Confidentiality was guaranteed, and teachers could withdraw at any time with no consequences or explanations required. As part of the informed consent process, teachers were informed that the study aimed to understand their motivation toward teaching and the association with different factors influencing and resulting from their reasons to teach. In addition, teachers were asked to provide information regarding age, gender, and teaching experience. For the latter, we categorized the vari- able in less or more than 10 years, as it has been suggested that reaching an expert level of performance in whatever skill requires over 10 years' involvement. ${ }^{18}$

\section{2 | Instruments}

Work climate was measured using the 6-item Spanish version of the Work Climate Questionnaire. ${ }^{19}$ This 1-dimensional instrument measures the autonomy support that teachers' perceive from their immediate supervisor (e.g., I feel that my supervisor provides me choices and options).

Teachers' perception of their students' autonomous and controlled motivation was measured using an adaptation of the 28-item Spanish version of the Academic Motivation Scale (e.g., Because they experience pleasure and satisfaction while learning new things). ${ }^{16,20}$ Autonomous and controlled motivation were merged into 1 index, ${ }^{4}$ where a positive score suggested an autonomous perception of students' motivation, and a negative score indicated a perception of controlled motivation. ${ }^{21}$

Basic needs satisfaction and frustration were measured using the 24-item Spanish version of the Basic Psychological Need Satisfaction and Frustration Scale. ${ }^{22}$ This instrument captures both the satisfaction and frustration of autonomy, competence and relatedness (e.g., In my job I do the things I do because I really want to do them). Need satisfaction and need frustration were merged into 1 score, where a positive index suggested basic needs perceived as satisfied, and a negative index suggested basic needs perceived as frustrated. ${ }^{23,24}$

Autonomous and controlled motivation toward teaching were measured using the 19-item Spanish version of the Multidimensional Work Motivation Scale. ${ }^{25}$ In order to explore reasons beyond salary, the instrument asks, "Why do you or would you put efforts into your current teaching job?" (e.g., Because the work I do is interesting). Autonomous and controlled motivation were merged into 1 index, where a positive score suggested autonomous motivation, and a negative score suggested controlled motivation toward the teaching job. 
Finally, teacher-and student-centered teaching approaches were measured using the 20-item Spanish version of the Approaches to Teaching Inventory (e.g., In teaching sessions for this course, I deliberately provoke debate and discussion). ${ }^{26}$ Both measures were merged into 1 index, where a positive score reflected a student-centered approach, and a negative score reflected a teacher-centered approach. The instruments contained a total of 97 items.

\section{3 | Data analysis}

The significance level was set at $\leq 0.05$, and all data analyses were conducted using the SPSS (version 22.00) and AMOS (version 20.0) software. Cronbach's alpha scores and Pearson's correlation coefficient were used to calculate internal consistencies and bivariate correlations. These were computed for all measures, along with descriptive scores. Finally, structural equation modeling (SEM) analysis was used to test the model's fit to the data and to interpret the hypothesized paths (Figure 1). ${ }^{27,28}$ In the model, we used the indexes mentioned above for parsimony. As there is no 1 standard score to a definite evaluation of SEM results, ${ }^{27}$ we conducted the following series of tests (acceptable cut-off score in parenthesis): the Chi-square test $\left(\chi^{2},>0.05\right)$, the root mean square error of approximation (RMSEA, $<0.08$ ), the comparative fit index (CFI, > 0.90), and the goodness-of-fit index (GFI, $>0.90) .{ }^{27}$ Standardized path scores of parameter estimates were interpreted as regression coefficients. In addition, mean differences with regards to gender, teaching experience, and type of university (private or public) were computed through independent $t$-tests with Holm-Bonferroni corrections. If significant, these variables would be added as controls since previous research has suggested their confounding effects on motivation. ${ }^{4,20}$

\section{3 | RESULTS}

The final sample consisted of 206 teachers $(80.4 \%$ response rate), with an average age of $42.61(\mathrm{SD}=10.68)$ and a gender distribution of 106 (52\%) women and 100 (48\%) men. A total of $161(78 \%)$ teachers taught at private institutions while $45(22 \%)$ taught at a public dental school. Furthermore, $106(52 \%)$ participants reported less than 10 years of teaching experience, while $100(48 \%)$ reported more than 10 years.

\section{1 | Reliability, descriptive scores, and correlations}

Table 1 shows the internal consistency of the scales, descriptive scores, and correlations for all variables. Alpha coeffi- cients were acceptable, ranging from 0.701 to 0.948 , suggesting the scales as reliable within the context of this study. ${ }^{29}$

For the total sample, an above-the-mean score was reported for the work climate $(\mathrm{M}=5.73, \mathrm{SD}=1.34)$. Teachers' perceived their students as more controlled $(\mathrm{M}=21.20$, $\mathrm{SD}=3.33)$ than autonomously motivated $(\mathrm{M}=19.36$, $\mathrm{SD}=3.66)$, reported higher need satisfaction $(M=6.00$, $\mathrm{SD}=0.75)$ than frustration $(\mathrm{M}=2.27, \mathrm{SD}=0.85)$, showed higher autonomous $(\mathrm{M}=6.41, \mathrm{SD}=0.69)$ over controlled motivation to teach $(\mathrm{M}=4.15, \mathrm{SD}=1.01)$, and reported a higher student- $(\mathrm{M}=39.41, \mathrm{SD}=5.17)$ rather than a teachercentered teaching approach $(\mathrm{M}=31.03, \mathrm{SD}=6.43)$.

Concerning correlations, a supportive work climate showed a positive association with teachers' need satisfaction $(r=0.58, P<0.01)$ and a negative association with teachers' needs frustration $(r=-0.23, P<0.01)$. With regard to teachers' perceptions of their students' motivation, controlled motivation $(r=0.31, P<0.01)$, and autonomous motivation ( $r=0.44, P<0.01)$ showed positive associations with teachers' need satisfaction. However, teachers' perception of students being autonomously motivated as opposed to controlled motivated showed a stronger positive correlation with teachers' need satisfaction. On the other hand, teachers' need frustration, showed a negative $(r=-0.23, P<0.01)$ and a non-significant $(r=0.08, P>0.05)$ association with their perception of students' autonomous and controlled motivation, respectively.

Moreover, teachers perceiving students as autonomously motivated showed a stronger positive correlation with their autonomy ( $r=0.34, P<0.01)$ rather than controlled motivation to teach $(r=0.23, P<0.01)$. The contrary results are shown for teachers' perception of students' controlled motivation. These results are similar to the correlations found between needs satisfaction/frustration and teachers' motivation to teach, where needs satisfaction showed stronger positive scores when correlated with teachers' autonomous motivation $(r=0.63, P<0.01)$ than with controlled motivation to teach $(r=0.21, P<0.01)$. The opposite can be observed concerning teachers' needs frustration.

Turning to teaching approaches, teacher's autonomous motivation to teach showed a positive correlation with a student-centered teaching approach $(r=0.40, P<0.01)$, while the association with teacher-centered teaching was negative $(r=-0.23, P<0.01)$. Teachers' controlled motivation to teach showed weak positive associations with both student$(r=0.15, P<0.01)$ and teacher-centered approaches to teach $(r=0.06, P>0.05)$.

\section{2 | Structural equation modeling}

The results from the SEM analysis showed that the hypothesized model fit the observed data well. The Chi-square test 
T A B L E 1 Bivariate correlations, internal consistency and means (standard deviation) of all measures

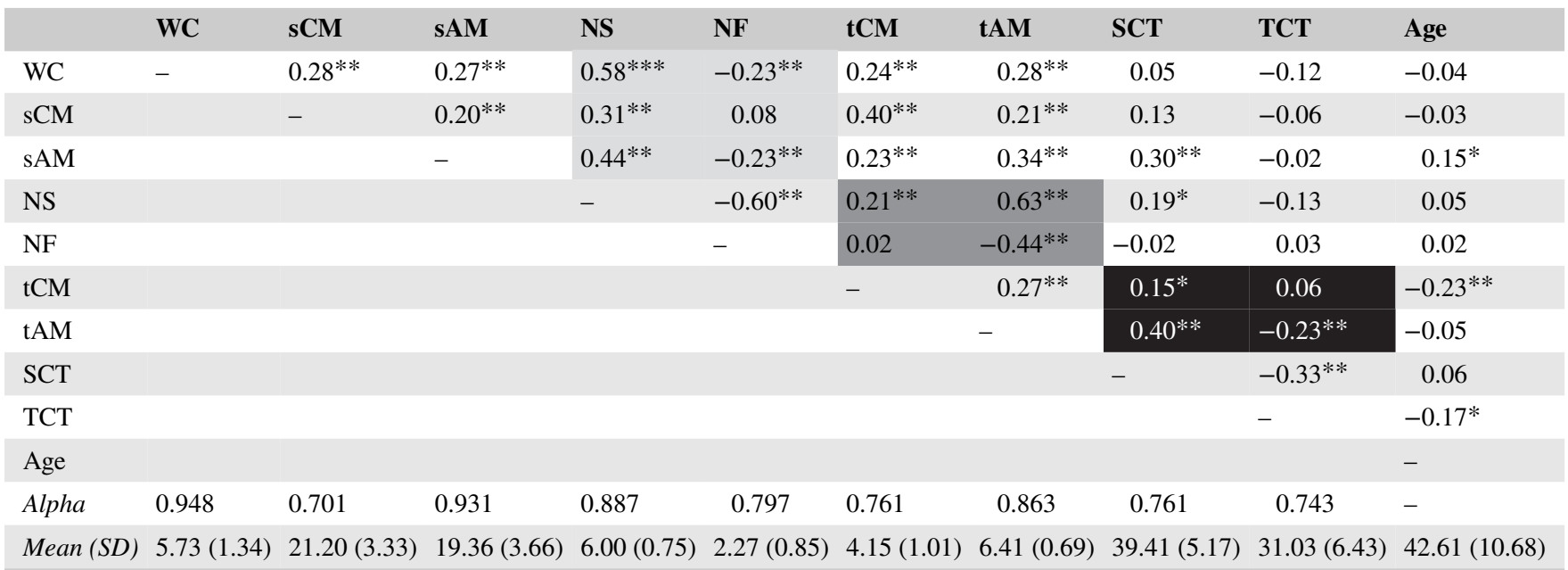

Note: WC, Work Climate; sCM, Perception of Students' Controlled Motivation; sAM, Perception of Students' Autonomous Motivation; NS, Teachers' Basic Needs Satisfaction; NF, Teachers' Basic Needs Frustration; tCM, Teachers' Controlled Motivation; tAM, Teachers' Autonomous Motivation; SCT, Student-Centered Teaching; TCT, Teacher-Centered Teaching. ${ }^{*} P<0.05$ (2-tailed), ${ }^{* *} P<0.01$ (2-tailed). Total sample of 206 clinical teachers. Light gray background correlation coefficients represent hypothesis 1 , dark gray background correlation coefficients represent hypothesis 2 , and black background correlation coefficients represent hypothesis 3 .

was non-significant $(\chi 2=8.195, d f=4, P=0.085)$, and the results from the RMSEA $(0.076,90 \% \mathrm{CI}=0.000,0.150)$, GFI (0.990), and CFI (0.987) were all above the acceptable cutoff score and, therefore, parameter estimates were retained. Group differences for gender, teaching experience, and type of university were significant; therefore, we decided to add these variables (along with age) as controls in the SEM analysis.

Figure 2 shows that all standardized regression paths were significant and in the hypothesized direction. First, a supportive work climate ( $\beta=0.44, P<0.001)$ and perceiving students' motivation as autonomous over controlled $(\beta=0.20$, $P<0.01$ ), positively predicted teachers' basic psychological needs satisfaction over frustration. In turn, the satisfaction over the frustration of the basic psychological needs positively predicted teachers' autonomous over controlled motivation to teach $(\beta=0.33, P<0.001)$. Finally, teachers' autonomous over controlled motivation to teach positively predicted a student- over a teacher-centered teaching approach $(\beta=0.17$, $P<0.01)$. Moreover, the coefficient of determination $\left(\mathrm{R}^{2}\right)$ suggests that the overall model explains $42 \%$ of the variance in teaching approaches.

\section{4 | DISCUSSION}

Despite the demanding tasks involved in clinical teaching, teachers' motivation has been an understudied area in health professions education as well as in general educational research. ${ }^{1,30}$ Our study, therefore, adds to the literature in this aspect showing support for the hypothesized model.
The results are consistent with hypothesis 1 and suggest that perceiving a supportive relationship with the direct supervisor and perceiving students as autonomously motivated as opposed to controlled is associated with an increase in teachers' satisfaction of their autonomy, competence, and relatedness and a decrease in these being frustrated. Previous studies have shown that teachers reported less satisfaction and more frustration of their basic psychological needs when perceiving their direct supervisors as unsupportive, controlling, and authoritative, and when perceiving students engagement mainly due to external reasons such as compliance, maintaining a certain standard, or because of internal or external pressure. ${ }^{16,30,31}$ It is import to clarify that both autonomous and controlled motivation represent intention to act, regardless of the initiating reasons; therefore, one would expect positive associations with teachers' need satisfaction.

Concerning hypothesis 2, our results provide evidence that, as teachers' perception of their basic psychological needs in the workplace is satisfied, their motivation to teach is associated with autonomous reasons. In turn, as their needs are perceived as less satisfied and more frustrated, their motivation is associated with controlled reasons to teach. These results concur with previous studies showing that a work environment that promotes teachers' perceptions of autonomy, competence, and relatedness may lead to more self-determination toward teaching, resulting in higher satisfaction, commitment, and value given to the teaching role. ${ }^{9,10,30,32}$

With regard to hypothesis 3 , our results suggest that experiencing autonomous motivation toward teaching predicts a student- over a teacher-centered teaching style. It can thus be 


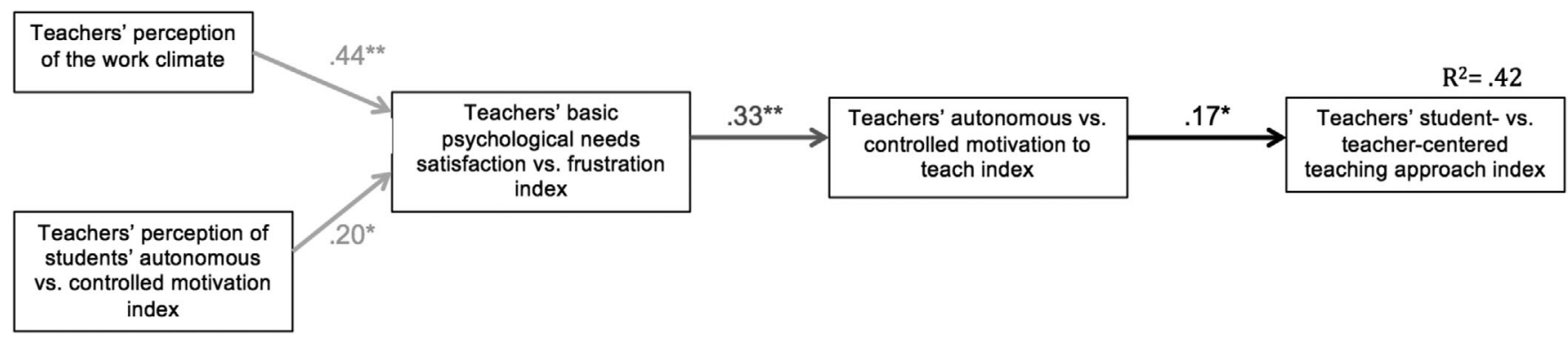

F I G U R E 2 Structural equation model showing standardized regression coefficients amongst the hypothesized model for all participants. Note: Structural equation model through the Maximum likelihood method. Residuals, covariances, and regression paths of control variables have been omitted to simplify the model's visualization. Significance in all paths are based on unstandardized regression coefficients, controlling for gender, age, teaching experience, and type of university. ${ }^{*} P<0.01,{ }^{* *} P<0.001$. Light gray paths and estimates symbolize hypothesis 1 , dark gray path and estimate symbolizes hypothesis 2 , and black path and estimate symbolizes hypothesis 3

suggested that teachers experiencing autonomous motivation are more likely to adopt a conceptual change and a meaningoriented teaching style rather than an information transfer or a reproductive-oriented approach. ${ }^{9,33,34}$ These results are in accord with recent studies showing that higher education teachers experiencing autonomous motivation find their work gratifying and significant, and report behaviors that support their students' basic psychological needs along with the use of exemplary teaching practices.9,30,35 For instance, supporting students' basic psychological needs included teachers justifying the reasons why students should engage in certain tasks; active listening and getting to know their students; providing constructive and timely feedback; considering each students' context and development; fostering peer- and self-assessment; and providing instances for self-directed learning. Exemplary teaching practices included fostering social learning; horizontal and vertical integration in their courses; instances to learn on how to reflect in and on action; and clear instructional plans.

The evidence from this study suggests that clinical teachers' optimal motivation is of paramount importance for promoting an adequate learning environment for students. Therefore, efforts should be made to understand and foster different aspects that promote teachers' satisfaction of their basic psychological needs and their autonomous motivation. These findings have significant implications for an initial understanding of how different factors from the clinical work environment influence teachers' motivation, and may serve as a starting point to develop faculty training instances and regulations that support teaching quality and teachers' wellbeing.

In this research, we have explored 2 factors that may influence teachers' basic psychological needs and their motivation: the work climate built by the teacher-supervisor relationship and students' motivation. The leadership and managing style by which supervisors relate to teachers may foster or diminish their motivation. ${ }^{15}$ Research has shown that, when supervi- sors adopt a transformational as opposed to a transactional leadership style, there is a positive impact on an individual's needs satisfaction and, subsequently on their motivation quality. ${ }^{31,36}$ This means that supervisors should avoid practices such as micromanaging and attempting to control teachers' behavior by means of rewards. Instead, supervisors' leadership style should focus on teamwork, a shared vision and collegiate decision-making, and caring for the professional and pedagogical development of their team members. The support and teamwork experience provided is especially relevant for dentists in teaching roles, where many of them may be working on a part-time basis mixing their teaching duties with heavy clinical practice workload. This may become an important barrier in building a sense of belongingness and commitment with the teaching role. There is, therefore, a definite need for supervisors to be trained and realize the influence they have on teachers' motivation and work quality.

In their day-by-day work, dental or other faculty in a leadership position may support colleagues' basic psychological needs in different ways. Research from an educational and business perspective points at supervisors being explicit on the reasons for their decision-making; facilitating resources for professional and pedagogical development; providing feedback and appraisal on teaching practices; providing teachers with choices on how to manage their administrative workload and on how to plan their teaching sessions; and providing instances to know and collaborate with other faculty members in order to foster a sense of community of teaching practice. ${ }^{1,15}$

We turn now to the second critical factor found to influence teachers' basic needs and motivation, which is teachers' perception of their students' motivation. Students and teachers are an integral part of the learning environment; therefore, SDT proposes that their behavior mutually influences one another. ${ }^{16}$ As such, teachers' motivation and what they do has an effect on students' basic psychological needs and 
motivation. In turn, students' motivation and behavior then feeds back into teachers' basic psychological needs satisfaction and subsequent motivation to teach. In other words, when teachers perceive that students are autonomously motivated toward their teaching sessions, they are more likely to experience need-satisfaction and an increase in their motivation quality to teach, and they may become more supportive of their students' basic psychological needs.

An important implication of this feedback loop is that both teachers and students are, in part, responsible for each other's motivation. Once again, this is especially relevant for the dental education environment, considering the vast amount of hours of direct one-on-one supervision in chairside teaching and small group learning activities. Consequently, the attitudes and behaviors of teachers and students toward one another may play a key role in their motivation and workplace experience.

Thus, how should awareness be raised on each other's role? As it was mentioned above, faculty development instances provide an important opportunity to train teachers on how to incorporate need-supportive teaching practices and become aware of the relevance of supporting students' autonomous rather than controlled motivation. ${ }^{37,38}$ Providing teachers with a new set of strategies to improve their teaching sessions and clinical supervision style may enhance their feelings of competence. This may have a positive impact on students' motivation, which is expected to positively feed back into teachers' motivation and satisfaction in the workplace. ${ }^{1}$ On the students' side, it is recommended to raise awareness of their role on teachers' motivation through induction instances or within learning-to-learn courses.

Despite the relevant findings in an unexplored area of health professions education, there are limitations that should be addressed. First, it was not possible to generalize our results beyond the dental schools involved, as they constituted a purposive sample of Chilean institutions. Second, the use of self-reported questionnaires could have favored desirable social answers; however, as confidentiality was assured and the questionnaires did not involve any sensitive information, we believe this does not represent a threat to the study's internal validity. Third, the exploratory nature of the study prevented from including additional factors that may influence and explain teachers' motivation and to analyze them through a longitudinal design. Finally, and despite including a series of control variables, there are still other factors that may potentially confound teachers' motivation. These may include personal characteristics, particularities of chairside teaching, peer support or pressure, patients' behavior and motivation, or the institution's criteria for promotions and rewards, all of which may play a significant role on clinical teachers' motivation. Consequently, there is ample room for further studies regarding clinical teachers' motivation, mainly considering the increasing liability held on teachers for students' outcomes and patient safety during training, and especially given the critical role they play in students' motivation.

\section{5 | CONCLUSION}

The present study aimed to explore clinical teachers' motivation along with relevant antecedents and consequences from the SDT perspective. Correlational analyses and structural equation modeling revealed that teachers' perceiving a work climate characterized by a supportive supervisor-teacher relationship and perceiving students' motivation as autonomous, positively predicted teachers' satisfaction of their basic psychological needs and subsequently predicted autonomous motivation to teach. This, in turn, was positively associated with a student- over a teacher-centered teaching approach. This study has been one of the first to thoroughly examine the process of teachers' motivation to teach in health professions education, supporting SDT's assertion that teachers' autonomous motivation is critical for students' learning. Therefore, efforts should be made to understand and foster different aspects that promote teachers' satisfaction of their basic psychological needs and autonomous motivation, especially regarding the role of teachers' supervisors and how teachers perceive their students' motivation.

\section{ACKNOWLEDGMENTS}

The authors thank all faculty staff for participating in this study, as well as the leadership of the involved Dental Schools and the Association for Dental Education in Chile (ACHEO) for their constant support.

\section{DISCLOSURE STATEMENT}

No potential conflict of interest was reported by the authors.

\section{ORCID}

Cesar A. Orsini DDS, MEd, FHEA, DHPE

https://orcid.org/0000-0002-5226-3625

\section{REFERENCES}

1. Pelletier L, Rocchi M. Teachers' motivation in the classroom. In: Chia Liu W, Chee Keng J, Ryan R, eds. Building Autonomous Learners. New York: Springer; 2016:107-127.

2. Orsini C, Binnie V, Wilson S. Determinants and outcomes of motivation in health professions education: a systematic review based on self-determination theory. J Educ Eval Health Prof. 2016;13: 19.

3. Orsini C, Binnie V, Jerez O. Motivation as a predictor of dental students' affective and behavioral outcomes: does the quality of motivation matter. J Dent Educ. 2019;83(5):521-529. 
4. Kusurkar R, Ten Cate O, Vos C, Westers P, Croiset G. How motivation affects academic performance: a structural equation modelling analysis. Adv Health Sci Educ Theory Pract. 2013;18(1): 57-69.

5. Orsini C, Binnie V, Wilson S, Villegas M. Learning climate and feedback as predictors of dental students' self-determined motivation: the mediating role of basic psychological needs satisfaction. Eur J Dent Educ. 2018;22(2):e228-236.

6. Sheldon K, Filak V. Manipulating autonomy, competence, and relatedness support in a game-learning context: new evidence that all three needs matter. Br J Soc Psychol. 2008;47:267283.

7. Deci E, Ryan R. The "What" and "Why" of goal pursuits: human needs and the self-determination of behavior. Psychol Inq. 2000;11(4):227-268.

8. Ten Cate O, Kusurkar R, Williams G. How self-determination theory can assist our understanding of the teaching and learning processes in medical education. AMEE Guide No 59 Med Teach. 2011;33(12):961-973

9. Ryan R, Deci E. Self-Determination Theory: Basic Psychological Needs in Motivation, Development, and Wellness. New York Guilford Publications; 2017:756.

10. Van den Berghe L, Soenens B, Aelterman N, Cardon G, Tallir I, Haerens L. Within-person profiles of teachers' motivation to teach: associations with need satisfaction at work, need-supportive teaching, and burnout. Psychol Sport Exerc. 2014;15(4):407417.

11. 11 Sarrazin P, Tessier D, Pelletier L, Trouilloud D, Chanal J The effects of teachers' expectations about students' motivation on teachers' autonomy-supportive and controlling behaviors. Int $J$ Sport Exerc Psychol. 2006;4(3):283-301.

12. Reeve J, Jang H. What teachers say and do to support students' autonomy during a learning activity. $J$ Educ Psychol. 2006;98(1):209-218.

13. Fernet C, Senécal C, Guay F, Marsh H, Dowson M. The work tasks motivation scale for teachers (WTMST). $J$ Career Assess. 2008;16(2):256-279.

14. Orsini C, Binnie V, Tricio J. Motivational profiles and their relationships with basic psychological needs, academic performance, study strategies, self-esteem, and vitality in dental students in Chile. J Educ Eval Heal Prof. 2018;15:11.

15. Fernet C, Guay F, Senécal C, Austin S. Predicting intraindividual changes in teacher burnout: the role of perceived school environment and motivational factors. Teach Teach Educ. 2012;28:514525.

16. Pelletier L, Séguin-Lévesque C, Legault L. Pressure from above and pressure from below as determinants of teachers' motivation and teaching behaviors. J Educ Psychol. 2002;94(1):186196.

17. ErdfelderE, Faul F, Buchner A. GPOWER: a general power analysis program. Behav Res Methods, Instruments, Comput. 1996;28(1):111.

18. Ericsson K. Deliberate practice and the acquisition and maintenance of expert performance in medicine and related domains. Acad Med. 2004;79(10):S70-S81.

19. Baard P, Deci E, Ryan R. Intrinsic need satisfaction as a motivational basis of performance and well-being at work: An application of cognitive evaluation theory. Unpublished manuscript, Fordham Univ New York. 2000.
20. Orsini C, Binnie V, Evans P, Ledezma P, Fuentes F, Villegas M. Psychometric validation of the academic motivation scale in a dental student sample. J Dent Educ. 2015;79(8):971981.

21. Deci E, Ryan R. Self-determination theory: a macrotheory of human motivation, development, and health. Can Psychol Can. 2008;49(3):182-185.

22. Chen B, Vansteenkiste M, Beyers W, et al. Basic psychological need satisfaction, need frustration, and need strength across four cultures. Motiv Emot. 2015;39(2):216-236.

23. Campbell R, Vansteenkiste M, Delesie L, et al. Examining the role of psychological need satisfaction in sleep: a self-determination theory perspective. Pers Individ Dif. 2015;77:199-204.

24. Haerens L, Aelterman N, Vansteenkiste M, Soenens B, Van Petegem S. Do perceived autonomy-supportive and controlling teaching relate to physical education students' motivational experiences through unique pathways? Distinguishing between the bright and dark side of motivation. Psychol Sport Exerc. 2015;16: 26-36.

25. Gagné M, Forest J, Vansteenkiste M, et al. The multidimensional work motivation scale: validation evidence in seven languages and nine countries. Eur J Work Organ Psychol. 2015;24(2):178196

26. Monroy F, González-Geraldo J, Hernández-Pina F. A psychometric analysis of the Approaches to Teaching Inventory (ATI) and a proposal for a Spanish version (S-ATI-20). An Psicol Psychol. 2015;31(1):172-183.

27. Kline R. Principles and Practice of Structural Equation Modeling. Structural Equation Modeling. New York: Guilford; 2010: 427.

28. Violato C, Hecker K. How to use structural equation modeling in medical education research: a brief guide. Teach Learn Med. 2007;19(4):362-371.

29. Warner R. Applied Statistics: From Bivariate Through Multivariate Techniques: From Bivariate Through Multivariate Techniques. Ney York: Sage; 2013:1208.

30. Stupnisky R, BrckaLorenz A, Yuhas B, Guay F. Faculty members' motivation for teaching and best practices: testing a model based on self-determination theory across institution types. Contemp Educ Psychol. 2018;53:15-26.

31. Eyal O, Roth G. Principals' leadership and teachers' motivation: self-determination theory analysis. $J$ Educ Adm. 2011;49(3):256275 .

32. Klassen R, Perry N, Frenzel A. Teachers' relatedness with students: an underemphasized component of teachers' basic psychological needs. J Educ Psychol. 2012;104(1):150-165.

33. Matsuyama Y, Nakaya M, Okazaki H, Lebowitz AJ, Leppink J, van der Vleuten $\mathrm{C}$. Does changing from a teacher-centered to a learner-centered context promote self-regulated learning: a qualitative study in a Japanese undergraduate setting. BMC Med Educ. 2019;19(1):152-164

34. Korthagen F, Evelein F. Relations between student teachers' basic needs fulfillment and their teaching behavior. Teach Teach Educ. 2016;60:234-244.

35. Jeno L, Langdon J. Are autonomously motivated university instructors more autonomy-supportive teachers. Int J Scholarsh Teach Learn. 2019;13(2):5.

36. Gagné M, Deci E. Self-determination theory and work motivation. J Organ Behav. 2005;26:331-262. 
37. Tessier D, Sarrazin P, Ntoumanis N. The effects of an experimental programme to support students' autonomy on the overt behaviours of physical education teachers. Eur J Psychol Educ. 2008;23(3):239-253.

38. Tessier D, Sarrazin P, Ntoumanis N. The effect of an intervention to improve newly qualified teachers' interpersonal style, students motivation and psychological need satisfaction in sportbased physical education. Contemp Educ Psychol. 2010;35(4): 242-253.
How to cite this article: Orsini CA, Tricio JA, Segura C, Tapia D. Exploring teachers' motivation to teach: A multisite study on the associations with the work climate, students' motivation, and teaching approaches. J Dent Educ. 2020;84:429-437.

https://doi.org/10.1002/jdd.12050 